SISTEMA
ELETRÔNICO
DE REVISTAS
SER I UfPR

\title{
Os comitês de bacias hidrográficas e o gerenciamento integrado na Política Nacional de Recursos Hídricos
}

\section{River basin committees and integrated management in the Brazilian National Water Resources Policy}

\author{
Luis Fabio Gonçalves MESQUITA ${ }^{1^{*}}$ \\ ${ }^{1}$ Programa de Pós-Graduação em Desenvolvimento Sustentável, Universidade de Brasília (UnB), Brasília, DF, Brasil. \\ *E-mail de contato: mesquita_4@hotmail.com
}

Artigo recebido em 19 de junho de 2016, versão final aceita em 7 de fevereiro de 2018.

RESUMO: A Política Nacional de Recursos Hídricos estabelece que a gestão hídrica no Brasil deve ser integrada e descentralizada com a participação do poder público, da sociedade civil e dos usuários de cada bacia. Nesse sentido, a política hídrica instituiu os Comitês de Bacia Hidrográfica, a fim de aproximar a tomada de decisão das comunidades locais. Contudo, estudos empíricos têm indicado que esse novo modelo de gestão é comprometido por interesses políticos, econômicos e por fragilidades administrativas. Os objetivos desse texto são (I) identificar e analisar os fatores que comprometem a participação dos membros dos comitês de bacia - utilizando o Comitê de Bacia Hidrográfica dos Afluentes do Rio Preto do Distrito Federal como estudo de caso; e (II) fazer uma abordagem crítica do gerenciamento integrado dos recursos hídricos. Os procedimentos metodológicos utilizados envolveram a pesquisa bibliográfica, com revisão da literatura pertinente à descentralização, à participação, à gestão, à integração dos recursos hídricos, a análise documental das atas do Comitê de Bacia Hidrográfica dos Afluentes do Rio Preto e, por fim, entrevistas semi-estruturadas com os membros do referido comitê. Foram identificados aspectos que comprometem a participação e a representatividade nos comitês, bem como o funcionamento dessas instituições. Também, foram evidenciadas as dificuldades de implementar o gerenciamento integrado dos recursos hídricos. Assim, concluiu-se que, para alcançar a sustentabilidade na gestão hídrica, existem algumas condições necessárias: a inclusão da discussão científica e tecnológica de caráter multidisciplinar; a equidade de poder e a colaboração entre os diferentes atores no processo de tomada de decisão.

Palavras-chaves: comitê de bacia hidrográfica; recursos hídricos; participação; gestão integrada; descentralização. 
ABSTRACT: Brazilian National Water Resources Policy establishes the integration and decentralization of water management so that public power, civil society and users of each basin can participate in the decisions. To this end, such policy instituted the River Basin Committees in order to approach local communities of the decision-making process. Nevertheless, empirical studies have shown that this new model of management is compromised by political and economic interests and by management vulnerabilities. This paper aims (i) to identify and analyze what factors compromise the participation of the members of the committees, using the river basin committee of the Rio Preto Tributary located in Distrito Federal as a study case and (ii) to critically approach the integrated management of water resources. The methodological procedures involved a bibliographic research, with a pertinent literature review on the decentralization, participation, management, and integration of water resources. Additionally, a documentary analysis of the minutes of the committee and semi-structured interviews with members of the committee were performed. The data revealed aspects that compromise both the participation and representativeness of the committees, and the functioning of these institutions. Moreover, difficulties of implementing the integrated management of water resources were highlighted. Results indicate three necessary conditions to achieve sustainability in water management, namely: a technological and scientific discussion in a multidisciplinary approach, equity of power, and collaboration among the different actors involved in the decision-making process.

Keywords: river basin committee; water resources; participation; integrated management; decentralization.

\section{Introdução}

Desde a década de 1980, a descentralização se tornou palavra de ordem no cenário internacional de políticas públicas. A maioria dos países em desenvolvimento tem promovido reformas que delegam maior poder político aos níveis territoriais mais locais (Agrawal \& Ribot, 2000). Diferentemente da desconcentração, em que atores locais continuam subordinados ao poder central, a descentralização política refere-se à transferência de poder decisório aos agentes que prestam contas às populações locais, normalmente por intermédio de eleições.

Essa nova alocação, de poder decisório, implica na redução de custos de transação, no melhor aproveitamento de informações, na maior capacidade de adaptação às necessidades locais e, por fim, na adequação dos custos em relação aos benefícios (Abers \& Jorge, 2005). Nesse sentido, em condições específicas, a descentralização pode ser entendida como um mecanismo de democratização, pressupondo que a sociedade local tenha maior capacidade de controlar as decisões políticas tomadas em nível local.

Contudo, estudos empíricos sobre a descentralização (que constam na literatura) mostram que nem sempre esse modelo é o mais eficiente e democrático. A eficiência pode ser prejudicada em duas circunstâncias: (I) quando instituições locais não têm capacidade técnica ou administrativa de deliberar ou executar efetivamente; ou (II) quando os interesses políticos locais são caracterizados por clientelismo, corrupção ou outros padrões que fazem com que as decisões políticas não sigam as prioridades técnicas (Arretche, 1996; Agrawal \& Ribot, 2000; Blair 2000; Brannstrom, 2004; Manor, 2004). A democracia é prejudicada quando elites locais conseguem monopolizar os processos decisórios ou quando a sociedade civil local não é bem organizada. 
Robinson (2007) chama a atenção para os potenciais riscos da descentralização. De acordo com o referido autor, não há garantia que a autonomia dada a governos locais implicará na melhoria de serviços públicos. O poder concedido a elites locais pode até comprometer a equidade social e a prestação dos serviços.

A descentralização da gestão dos recursos hídricos no Brasil, sacramentada com a instituição da Lei ${ }^{0} 9.433$ de 08 de janeiro de 1997 (que cria a Política Nacional de Recursos Hídricos - PNRH e o Sistema Nacional de Gerenciamento de Recursos Hídricos - SNGRH), iniciou-se com a acentuação de processos de degradação dos recursos hídricos. Áreas de maior concentração urbano-industrial-agrícola foram sedes de discussões envolvendo esferas do poder público, associações de profissionais relacionados às questões dos recursos hídricos e setores organizados da sociedade civil.

Essa abordagem mais ampla possibilita a participação não apenas de diferentes órgãos do Estado, mas também da sociedade (Jacobi, 2009). A PNRH criou os Comitês de Bacias Hidrográficas - CBH, compostos por membros do poder público, da sociedade civil e de usuários das respectivas bacias. Teoricamente, essa nova forma de gestão aproximaria as demandas locais da tomada de decisão, seguindo a lógica descentralizadora da política hídrica.

O objetivo desse texto é identificar e analisar os fatores que comprometem a operacionalidade e a participação nos CBHs e, também, fazer uma análise crítica do gerenciamento integrado dos recursos hídricos. Além desta introdução, o texto está dividido em mais seis partes: I) procedimento metodológicos; II) histórico da gestão das águas no Brasil; III) caracterização e participação dos comitês de bacia hidrográfica, incluindo o Comitê de Bacia Hidrográfica dos Afluentes do Rio Preto - CBH-AP; IV) análise crítica do gerenciamento integrado dos recursos hídricos; V) desafios da gestão descentralizada e integrada dos recursos hídricos; e, por fim, VI) a conclusão.

\section{Procedimentos metodológicos}

Para alcançar os objetivos deste artigo, foram realizadas consultas a referências bibliográficas, pesquisa documental, observação não participante e entrevistas com membros do Comitê de Bacia Hidrográfica dos Afluentes do Rio Preto. O recorte da análise desta pesquisa destinou-se a avaliar a eficiência da gestão descentralizadora trazida pela política hídrica. Foi feita uma revisão da literatura referente à gestão dos recursos hídricos no Brasil e da atuação dos comitês sob os diferentes aspectos - especialmente a participação dos atores que compõem esses comitês. A revisão da literatura aborda, também, o gerenciamento integrado dos recursos hídricos, destacando a complexidade de sua implementação.

A análise dos estudos consultados procurou (I) investigar a operacionalidade nos comitês de bacias e as condições de participação dos atores envolvidos nessas instituições (utilizando o Comitê de Bacia Hidrográfica dos Afluentes do Rio Preto como estudo de caso); e (II) avaliar a articulação entre a gestão hídrica e ambiental na tomada de decisão.

Considerando a diversidade de aspectos econômicos, sociais e ambientais nas áreas de atuação dos comitês, foi examinado se estas instituições compartilham os mesmos problemas. Os dados usados na análise foram extraídos de artigos científicos, 
livros, dissertações, teses e sites oficiais de instituições governamentais. Esta pesquisa bibliográfica pretendeu recuperar o conhecimento científico acumulado sobre a descentralização, a participação e a integração na gestão dos recursos hídricos, no âmbito da Política Nacional de Recursos Hídricos.

Com relação à pesquisa documental, foram analisadas as atas de reunião (36 atas no total) do Comitê de Bacia Hidrográfica dos Afluentes do Rio Preto-CBH-AP - localizado no Distrito Federal - no período do ano de 2010 ao primeiro trimestre 2017. As atas de reunião permitem verificar a participação dos membros do CBH-AP nas deliberações, proposições, resolução de conflitos e nas discussões que surgem no âmbito da área de atuação do comitê.

Além da pesquisa documental, foram realizadas entrevistas - baseadas em roteiro semi-estruturado - com 18 membros do CBH-AP (10 membros representavam o poder público, 05 a sociedade civil e 03 os usuários de água na bacia). Adotou-se, também, a metodologia da observação não participante em que se participou de 06 reuniões ordinárias e extraordinárias, realizadas pelo $\mathrm{CBH}-\mathrm{AP}$ no ano de 2016 e no primeiro trimestre do ano de 2017.

\section{Gestão dos recursos hídricos no Brasil}

No Brasil, a gestão hídrica tem sido historicamente voltada para os setores de energia elétrica, processamento industrial e irrigação. Por muito tempo, a provisão de serviços adequados de abastecimento de água, bem como o tratamento de efluentes despejados nos rios, não foram prioridades de gestão (Jacobi, 2006). O setor elétrico mantém, ainda, um domínio significativo na gestão hídrica e, muitas vezes, aproveita os direitos de concessão de uso sobre a água sem levar em conta aspectos sociais e ambientais. Um exemplo claro disso é o da construção da Usina de Belo Monte.

Considerando as denúncias de ONGs e do Ministério Público Federal no seu processo de licenciamento ambiental, há inconsistências no Estudo de Impacto Ambiental-EIA no que tange aos impactos sofridos pela fauna e flora, pelas populações ribeirinhas e pelas comunidades indígenas locais. Além do tratamento superficial a mecanismos de mitigação e compensação desses impactos. Mesmo diante da negligência de avaliação dos impactos socioambientais, o empreendimento recebeu a licença de operação do órgão ambiental federal - o Instituto Brasileiro do Meio Ambiente e Recursos Naturais Renováveis (IBAMA, 2015).

A descentralização na gestão dos recursos hídricos ocorreu em um contexto de redução do estado brasileiro. Desde a década 1980, diversas políticas setoriais brasileiras têm passado por reformas que combinam a descentralização com a instituição de conselhos - como os de educação, de habitação, de saúde, de assistência social, de meio ambiente e de recursos hídricos. A Constituição Federal (1988), estabeleceu um marco no que concerne à gestão hídrica: a extinção do direito privado sobre a água, passando o direito de propriedade da água para a União e para os Estados (Jacobi, 2006). Essa nova configuração institucional introduz complexidade na gestão, pois a tomada de decisão centralizada foi dividida por diversas agências - nem sempre com interesses convergentes.

A dominialidade pública da água não transforma o poder público federal e estadual em proprietário da água, mas o torna gestor desse bem em nome do interesse público. Dessa forma, o estado passa a regular o uso da água e torna-se responsável pela 
elaboração de políticas que estabeleçam diretrizes e objetivos sustentáveis para o uso deste recurso.

A lei que instituiu a PNRH, também conhecida como Lei das Águas, criou o SNGRH, regulamentando o artigo constitucional que previa a sua criação. A referida lei introduziu novos fundamentos da gestão da água, tais como: (I) o domínio público da água; (II) recurso natural limitado e dotado de valor econômico; (III) os usos múltiplos da água; (IV) a bacia hidrográfica como unidade de planejamento; e (V) a gestão descentralizada com participação do poder público, dos usuários e das comunidades locais.

As diretrizes desta nova proposta estabelecem que os problemas relacionados à água devem ser resolvidos, em sua maioria, mediante um processo de negociação política e social, envolvendo diferentes níveis de governo e atores sociais. Mas, para que esta proposta se concretize, é necessário superar os limites do processo de negociação que existem em função do déficit de articulação entre as instâncias de gestão dos recursos hídricos e os governos locais. Os déficits de comunicação e participação dos diferentes atores envolvidos também precisam ser superados (Fracalanza et al., 2009).

A concepção de usos múltiplos da água minimizou o comando do setor elétrico na gestão hídrica e deu apoio à participação pública, em especial aos usuários e à sociedade civil. Assim, dando maior legitimidade às deliberações e fortalecendo as decisões tomadas (Prota, 2011). Para possibilitar a execução da PNRH, foram instituídos instrumentos de gestão, tais como os planos de recursos hídricos; o enquadramento dos corpos de água em classes de acordo com os usos preponderantes; as outorgas de direito de uso de recursos hídricos e a cobrança pelo uso dos recursos hídricos.
Os planos de recursos hídricos são planos diretores de longo prazo que estabelecem as diretrizes de gerenciamento dos recursos em nível de bacia hidrográfica, estado ou país. O conteúdo desses planos deve conter: I) os usos múltiplos e prioritários dos recursos hídricos; II) o diagnóstico e a estimativa do balanço de disponibilidade de água e demandas futuras; III) as metas de racionalização de uso e melhoria de qualidade; IV) análise de cenários de crescimento demográfico, evolução de atividades produtivas e de modificações de padrões de ocupação do solo. Considerando o conteúdo do plano de recursos hídricos, sua elaboração e sua execução, exige-se transparência. Além de participação da sociedade e dos atores envolvidos, bem como articulação com outras políticas setoriais (ambiental, agrícola, uso e ocupação do solo e saneamento básico).

O enquadramento dos corpos de água em classes tem o objetivo de assegurar a qualidade da água e, também, a sua compatibilidade com usos mais exigentes a que forem destinadas, a fim de reduzir os custos de combate à poluição da água mediante ações preventivas permanentes.

A outorga de direito de uso dos recursos hídricos é um instrumento pelo qual o Poder Público autoriza o usuário a utilizar as águas de seu domínio, seja por captação ou derivação, lançamento de efluentes ou geração de energia. Esse instrumento busca assegurar o controle quantitativo e qualitativo do uso da água. Além do exercício de direito ao acesso a esse recurso natural.

Por fim, a cobrança pelo uso da água tem por finalidade reconhecer a água como um bem dotado de valor econômico, além de incentivar o seu uso racional e gerar recursos financeiros para financiar programas, estudos e intervenções contempladas 
nos planos de recursos hídricos (ANA, 2011). Ainda, a Lei das Águas instituiu o instrumento do sistema de informação sobre recursos hídricos, responsável pela coleta, armazenamento e recuperação de informações sobre os recursos hídricos.

Para executar a PNRH, a Lei das Águas criou o SNGRH - composto pelo Conselho Nacional e Conselhos Estaduais/Distrital de Recursos Hídricos; pela Agência Nacional da Águas - ANA; pelos Comitês de Bacia Hidrográficas; pelos órgãos públicos federais, estaduais e municipais cujas competências se relacionem com a gestão hídrica; e pelas Agências de Água. A Figura 1 ilustra a matriz institucional do sistema.

Dentre os organismos presentes na matriz exposta abaixo, será dada maior ênfase aos Comitês de Bacia Hidrográfica-CBHs, que têm funções deliberativas, normativas e consultivas a nível local. Dentre as suas funções deliberativas, destacam-se a aprovação dos planos de recursos hídricos, a implantação da cobrança e, também, a decisão - em primeira instância - dos conflitos de uso de água na bacia hidrográfica (Prota, 2011).

O modelo de gerenciamento descentralizado e participativo inspirou-se no modelo francês de gestão de águas. Na França, o modelo descentralizado de gerenciamento das águas foi criado pela Lei $\mathrm{n}$ ${ }^{0} 64.1245$ (16/12/1964), que tratou do regime e da repartição das águas, da luta contra a sua poluição, do controle da qualidade da água, do estabelecimento de padrões aceitáveis e da criação de perímetros de proteção de mananciais (Fracalanza \& Campos, 2010). A lei adota a bacia hidrográfica como unidade de gerenciamento, o plano plurianual de ação na bacia e a cobrança direta dos usuários da água, visando à autonomia financeira do sistema. Foram criados organismos responsáveis pelo modelo em nível nacional (Estado francês e Comitê Nacional

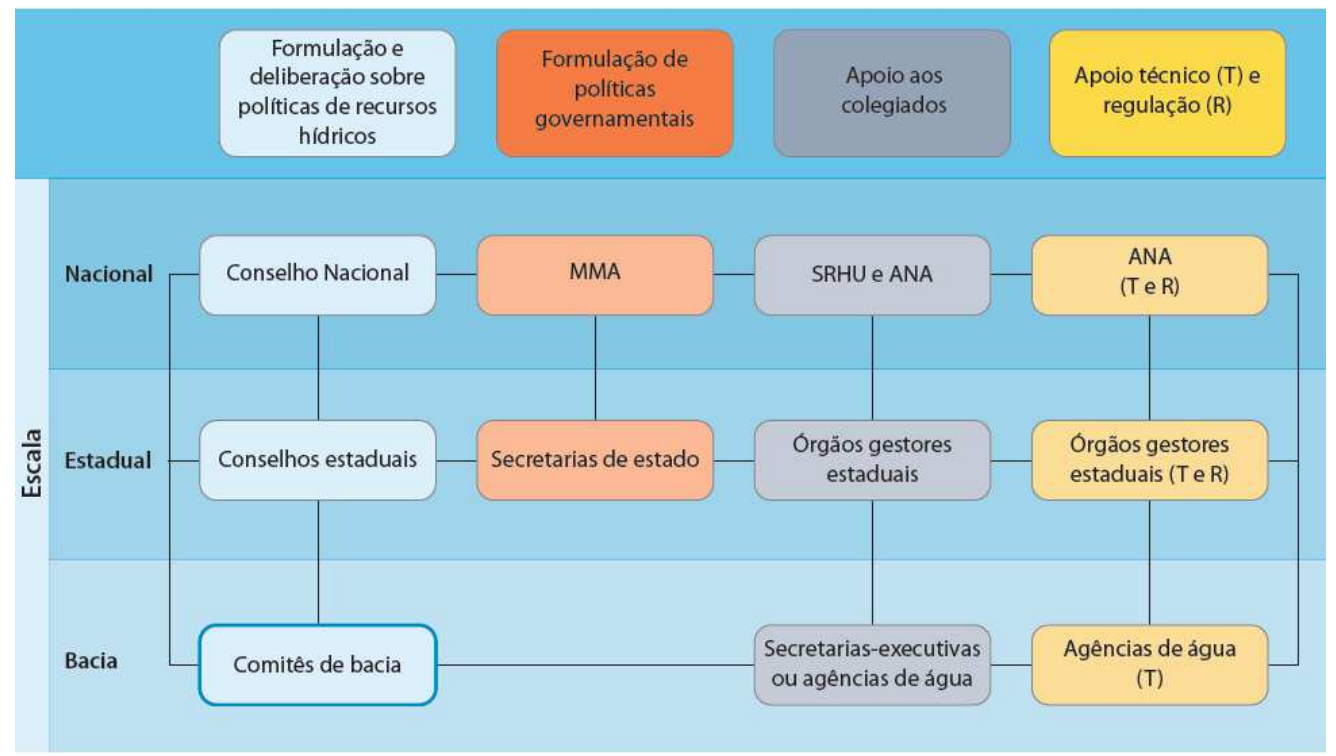

FIGURA 1 - Matriz institucional do Sistema Nacional de Gerenciamento dos Recursos Hídricos-SNGRH. FONTE: ANA (2011). 
das Águas) e em nível regional (comitês e agências de bacias).

Na seção seguinte, serão abordados estudos empíricos, o estudo de caso do Comitê de Bacia Hidrográfica dos Afluentes do Rio Preto, dados de instituições governamentais brasileiras que exploram a participação dos diferentes atores nos $\mathrm{CBHs}$, e - por fim - quais são os motivos da criação destas instituições.

\section{Comitês de bacia hidrográficas: novo paradigma na gestão}

Os especialistas consideram a experiência francesa a fonte de inovação no campo dos recursos hídricos. Várias ferramentas utilizadas na França têm sido apontadas pelas agências multilaterais como efetivas e úteis para o gerenciamento dos recursos hídricos - elas combinam regulação pública com mecanismos de mercado (Fracalanza \& Campos, 2010). Contudo, a replicação desse modelo em outros contextos deve ser feita com cautela. É preciso considerar o que permitiu a criação das agências de bacia da França, como elas evoluíram e quais são os conflitos conexos. A princípio, houve uma rejeição das autoridades locais francesas com relação às agências de bacias - consideradas tecnocráticas e sem legitimidade.

No contexto brasileiro, o crescimento do uso da água pelos diversos setores industriais, agrícolas, saneamento básico, energia, bem como o crescimento desordenado das cidades, reforçaram a necessidade de criação de arranjos institucionais similares ao modelo francês (observadas as especificidades de cada região). Os comitês de bacia fazem parte desses arranjos que visam arbitrar os conflitos de uso da água e aproximar as demandas das comunidades locais da tomada de decisão. Portanto, inicialmente, é válido investigar o motivo da criação dos comitês de bacia hidrográfica no Brasil.

\subsection{Disseminação dos comitês}

Para iniciar a explicação do processo de criação de comitês de bacia hidrográfica no Brasil, vale ressaltar a experiência vivenciada no Rio Grande do Sul. Em 1985, denúncias de contaminação do rio dos Sinos intensificaram-se, mobilizando a sociedade local e os técnicos da Fundação Estadual de Proteção Ambiental Henrique Luis Roessler (FEPAM), alertando-os sobre a necessidade de fortalecer a fiscalização e o controle dos lançamentos de efluentes nos corpos d'água da bacia. Em 1987, grupos organizados da sociedade, de universidades e de técnicos do estado realizaram um seminário sobre a questão. Foi proposta, neste evento, a criação do "Comitê de Preservação, Gerenciamento e Pesquisa da Bacia do Rio dos Sinos". O comitê foi criado no ano seguinte pelo Decreto Estadual $n^{\circ}$ 32.774, de 17 de março de 1988.

A composição do comitê não se limitava a governantes e técnicos governamentais. Além disso, faziam parte dele universidades, movimentos ecológicos, entidades empresariais, prefeituras municipais, câmaras de vereadores e organizações da sociedade civil. Apesar de uma experiência semelhante ter ocorrido em 1989, no Estado de São Paulo, com a criação do consórcio Consórcio Intermunicipal das Bacias dos Rios Piracicaba, Capivari e Jundiaí - PCJ, o movimento de criação do comitê na Bacia do Rio Sinos é considerado a primeira experiência brasileira na instituição de 
comitê de bacia inspirada no modelo francês (ANA, 2011). Nesse processo, o modelo adotado para a criação do comitê foi bottom up, ou seja, partiu da sociedade, dos usuários e dos especialistas, conferindo legitimidade à sua instituição. Esse modelo de gestão viabiliza o atendimento a demandas locais e está em consonância com os fundamentos de gestão descentralizada e participativa previstos na PNRH.

Com a promulgação da Constituição Federal de 1988, da Lei das Águas (1997) e da Lei ${ }^{0}$ 9.984 de 17 de julho de 2000, que criou a Agência Nacional Águas-ANA, houve uma proliferação de criação de comitês de bacia hidrográfica. A Figura 2, localizada abaixo, mostra a quantidade de comitês de bacia criados a partir do ano de 1994.
Atualmente, existem 218 comitês de bacia hidrográfica estaduais, sendo que 211 estão instalados (ANA, 2015). Uma análise de um estudo de caso sobre o processo de criação de comitês focalizou um conjunto de 15 comitês criados e um comitê em processo de formação (nas regiões Nordeste, Centro-oeste, Sul e Sudeste). Abers \& Jorge (2005) perceberam que uma das principais motivações para a criação desses comitês foi a vontade do governo estadual de se adequar às novas leis de recursos hídricos. A motivação financeira parece ter sido menos importante nesse caso, embora organismos de cooperação internacional como o BID e o Banco Mundial tenham promovido a criação de comitês e financiado vários organismos estudados. Da mesma

\section{Comitês de Bacias Hidrográficas Estaduais}

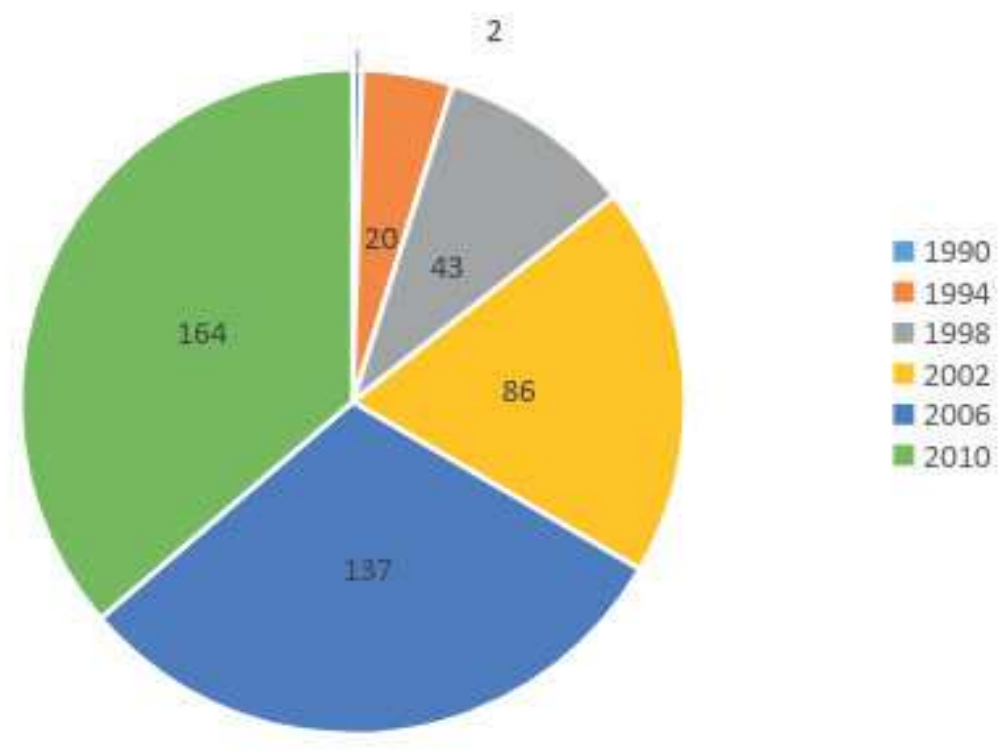

FIGURA 2 - Número de Comitês Estaduais de Bacia Hidrográficas no Brasil no período de 1994 a 2010.

FONTE: Adaptado de ANA (2011). 
forma, a Agência Nacional de Águas tem exigido a criação de comitês como requisito para oferecer apoio financeiro. O estudo aponta outras motivações para a criação de comitês, como conflitos pelo uso da água, eventos críticos (inundações e secas) e o agravamento das condições ambientais da bacia. Evidentemente, essa pesquisa não exauriu todas as motivações para instituir os comitês de bacia hidrográfica, mas evidencia que a criação dessas instituições é dinâmica.

A disseminação de comitês pelo país não garante a sua democratização e legitimidade. Segundo Ribot (2007), a proliferação de instituições locais pode causar fragmentação ou difusão do poder público.

Portanto, a criação dos CBHs ocorre por diferentes motivos, podendo ser: (I) aspectos financeiros; (II) conflitos; (III) negociações entre os atores envolvidos; (IV) determinação legal; ou (V) eventos críticos. Essa dinâmica se relaciona com as diversas finalidades de usos dos recursos hídricos na indústria, na agricultura, no saneamento básico e na proteção ambiental. Considerando essa diversidade de interesses, a efetiva participação e a representatividade dos membros dos comitês são fatores críticos para garantir a democratização e a resolução de conflitos. Contudo, interesses políticos, econômicos e fragilidades administrativas podem comprometer o alcance dessa gestão democrática.

\subsection{Participação nos comitês}

Conforme visto, a composição de um comitê deverá refletir os múltiplos interesses com relação às águas da respectiva bacia. De forma geral, são três os interesses que se expressam nas bacias: os dos usuários diretos de recursos hídricos (sujeitos ou não à outorga de direito de uso); os dos poderes públicos (municípios, estados e União) constituídos na implementação das diferentes políticas públicas; e os das organizações civis na defesa dos interesses coletivos. Soma-se, com essa diversidade, o fato de que cada setor citado, por sua vez, abarca outros múltiplos interesses.

De acordo com a Lei das Águas, os membros do poder público se limitam a $50 \%$ do total de membros no comitê, a fim de conferir paridade entre os atores. Contudo, essa paridade é questionada por diversos autores. Na prática, não ocorre equilíbrio entre o número de representantes do poder público, dos usuários e das organizações da sociedade civil (Prota, 2011). Não raramente o poder público supera o limite de $50 \%$, comprometendo a participação de outros setores.

É preciso compreender o funcionamento dos CBHs para fazer uma análise mais apurada. As deliberações dos comitês são decididas em plenário, que tem apoio de câmaras técnicas específicas. Essas câmaras têm caráter consultivo e podem ser compostas por membros indicados, geralmente especialistas, que não integram o comitê. A Figura 3 ilustra a estrutura do Comitê de Bacia Hidrográfica do Rio São Francisco - CBHSF, um exemplo da estrutura organizacional de um comitê de bacia interestadual.

De acordo com estudos empíricos, o planejamento e a tomada de decisão nos comitês, apesar do conceito descentralizador e participativo dessas organizações, ocorrem de forma pouco democrática. Alguns problemas, evidenciados no estudo de caso de Prota (2011), em que a autora avalia o Comitê de Bacia Hidrográfica do Tietê - Jacaré (São Paulo), 
podem ser aqui mencionados para demonstrar o comprometimento da participação:

- Ausência de membros da sociedade civil nas reuniões, por serem realizadas em horários de trabalho;

- Fraca participação do estado;

- Ausência de instituição federal (IBAMA) e de representantes de moradores de baixa renda ou excluídos;
- Desproporcionalidade entre os setores representados nos comitês;

- Despesas com deslocamento, alimentação e diárias;

- Falta de comprometimento de alguns representantes.

Os problemas de participação, identificados no comitê do Tietê - Jacaré, também são observados em outros comitês. Na pesquisa de Moreira (2013),

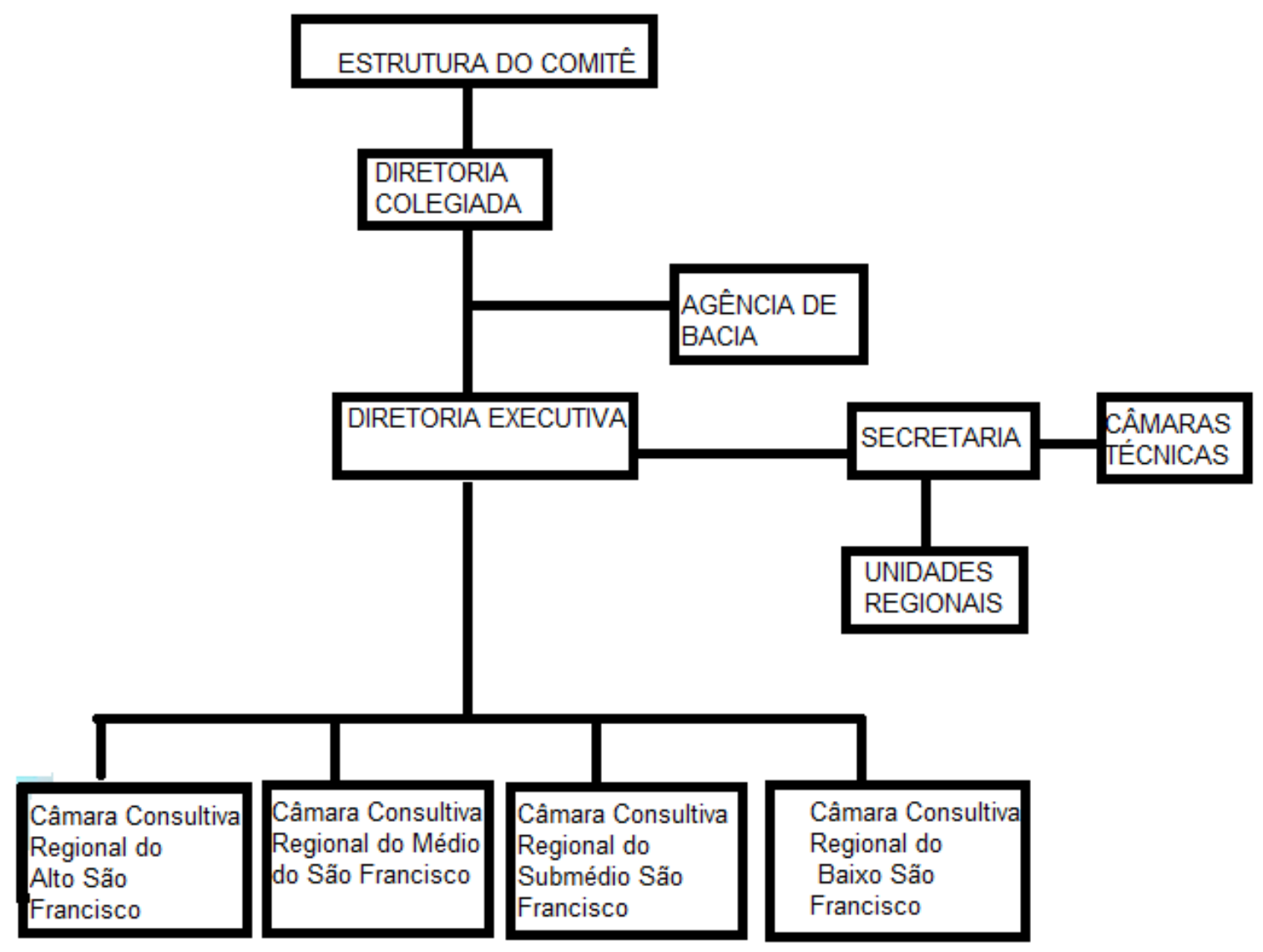

FIGURA 3 - Estrutura organizacional do Comitê de Bacia Hidrográfica do Rio São Francisco. FONTE: CBHRSF (2016). 
foi relatado que o Comitê de Bacia Hidrográfica do Baixo Jaguaribe (Ceará) fez um diagnóstico do seu próprio funcionamento. Foram aplicados 32 questionários em nove municípios da bacia em 2004 - 2005, visando avaliar seis anos de gestão do colegiado (1999 a 2005). Foi constatada a insatisfação dos membros do comitê com a atuação da Secretaria de Recursos Hídricos do Estado do Ceará, isso ocorreu devido à falta de apoio e consideração às demandas do comitê. A falta de comunicação entre os membros do comitê e da própria comunidade e a necessidade de divulgação do trabalho do comitê também foram constatados como fatores que comprometem seu funcionamento.

A pesquisa de Schultze et al. (2015) detectou a baixa representatividade do Comitê da Bacia Hidrográfica do Rio São Francisco (CBHSF) entre a população local e falhas na interação das instituições locais de gestão de água. O processo de transposição do rio São Francisco tem provocado discussões pertinentes sobre o ecossistema, sua sustentabilidade, a quantidade de água e a socioeconomia microrregional e nacional. A tomada de decisão sobre esse processo de transposição foi negociada sem que o Conselho Nacional de Recursos Hídricos levasse em consideração o posicionamento contrário do CBHSF ao projeto da transposição, iniciado pelo Ministério da Integração. O processo de participação foi questionado e criticado por todas as escalas.

\subsection{Comitê de Bacia Hidrográfica dos Afluentes do Rio Preto}

A área de atuação do Comitê de Bacia Hidrográfica dos Afluentes do Rio Preto -CBH-AP, criado no ano de 2010, está localizada na porção leste do território do Distrito Federal, inserida na Bacia Hidrográfica do Rio Preto - que faz parte da Bacia Hidrográfica do Rio São Francisco. A Bacia Hidrográfica do Rio Preto compreende uma área de aproximadamente 1.045.900 hectares, dividida entre os Estados de Goiás, Minas Gerais e do Distrito Federal (Figura 4).

$\mathrm{Na}$ área de atuação do $\mathrm{CBH}-\mathrm{AP}$, predominam atividades agrícolas com uso intensivo de pivôs centrais de irrigação que têm contribuído para a redução da disponibilidade hídrica para os usuários da bacia, principalmente no período de estiagem (Machado, 2009). Nesse período, a demanda por uso de água para irrigação agrícola em algumas unidades hidrográficas da bacia do Rio Preto é maior que a disponibilidade de água.

No ano de 2016, o governo distrital decretou estado de emergência nas áreas agrícolas de sua jurisdição devido à redução nos volumes de chuva nos meses de fevereiro, março e abril. A produção agrícola na bacia do Rio Preto, responsável por $80 \%$ da produção agrícola do $\mathrm{DF}$, foi afetada com a redução de - aproximadamente - $30 \%$ da área irrigada devido à falta de água (Mesquita, 2017).

As principais culturas irrigadas - cultivadas na bacia - são a soja, o milho, o feijão e o sorgo, principalmente pelos grandes irrigantes. Os pequenos produtores cultivam pimentão, alho, batata, cebola, hortaliças e tomate. Devido à redução das precipitações; à ausência de planejamento de longo prazo; ao uso irracional da água e as ocupações irregulares; o Distrito Federal enfrentou nos anos de 2016/2017 uma escassez de água sem precedentes. A "crise hídrica" que, na visão de alguns especialistas é uma crise de gestão, se instalou no DF com os níveis dos dois principais reservatórios de abastecimento humano abaixo de qualquer medição já registrada. 
Portanto, considerando o cenário hídrico crítico apresentado acima, as instituições responsáveis pela gestão dos recursos hídricos (como é o caso do CBH-AP) têm o dever de se organizar e direcionar esforços para amenizar esse cenário. Contudo, o CBH-AP enfrenta diversas dificuldades operacionais e de gestão. Há um predomínio de membros representantes do setor agrícola (grandes e médios irrigantes) e do poder público; não há membros representantes da sociedade civil de proteção ambiental, do meio acadêmico e nem de pequenos produtores.

Dessa forma, os assuntos debatidos no comitê concentram-se nos anseios de grandes produtores (obras de infraestrutura hídrica como barragens) e em procedimentos de regularização da propriedade pelo poder público - licenciamento ambiental e outorga de uso de água (Figura 5). Pouco se debate sobre a elaboração e execução do plano de bacia, sobre a captação de recursos financeiros para executar

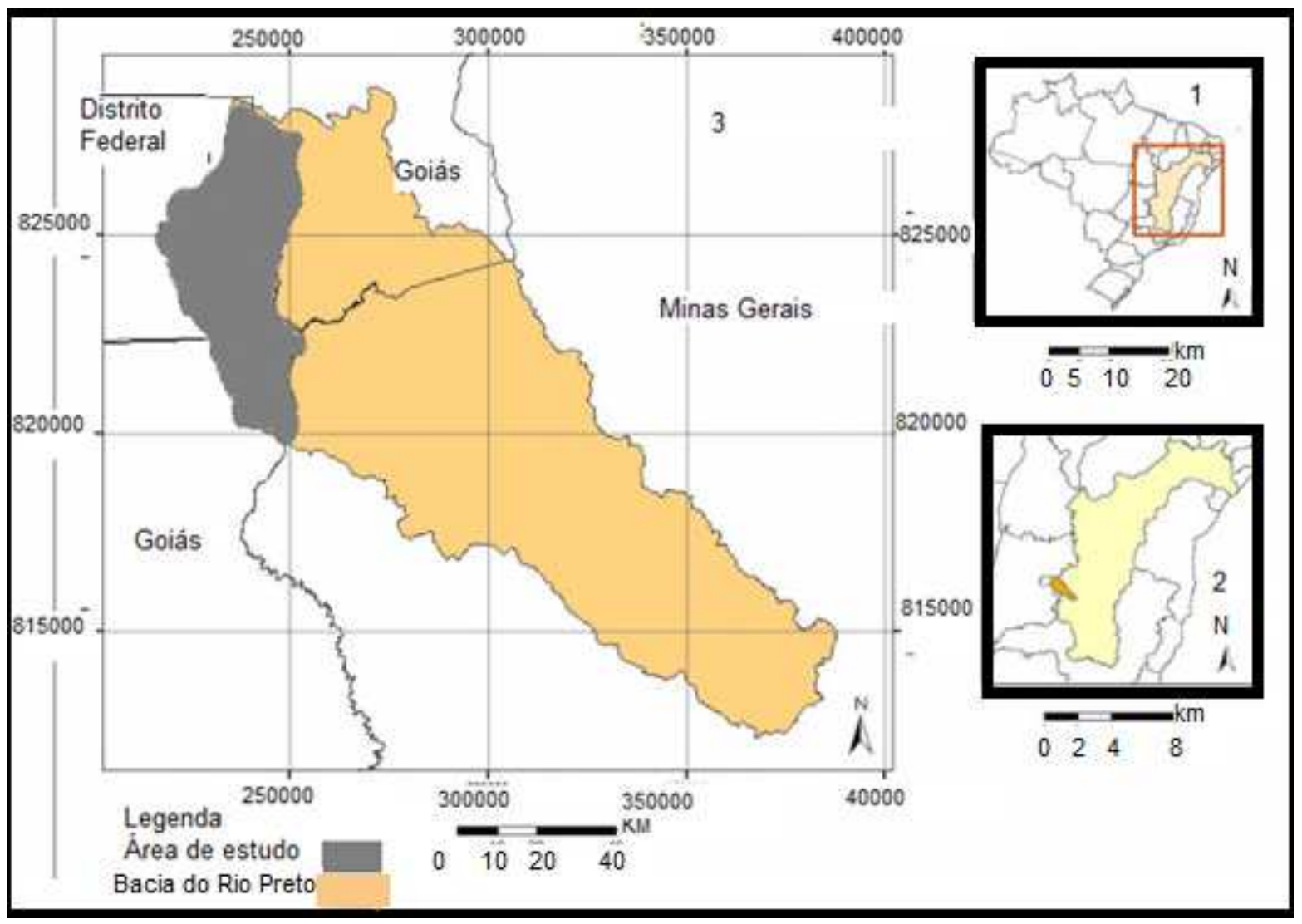

FIGURA 4 - Localização da Bacia Hidrográfica do Rio Preto (3) em relação à Bacia Hidrográfica do Rio São Francisco (1 e 2). FONTE: Adaptado de Borges (2008). 
projetos de interesse coletivo ou sobre a ampliação da participação de outros segmentos no comitê.

$\mathrm{Na}$ realidade, considerando as atribuições normativas do CBH-AP, constata-se que essa instituição ainda não consegue desempenhar essas atribuições de maneira satisfatória. Dentre as atribuições não executadas destacam-se: I) elaboração e execução do plano de bacia; II) aprovar projetos na bacia; III) sugerir mecanismos de cobrança pelo uso da água; e IV) arbitrar os conflitos pelo uso da água.

Os fatores que alimentam essa falta de operacionalidade no comitê são a ausência de recursos financeiros, o desconhecimento das funções do comitê, a representatividade dos membros e a falta de participação da academia, de entidades ambientais, de pequenos produtores e da comunidade local. É possível que o afastamento dos pequenos produtores e da comunidade local se dê pela falta de conhecimento sobre a existência do comitê e, também, sobre saber qual sua função na bacia. Outra possibilidade é considerar que isso ocorra pela dificuldade de participar das reuniões, seja pelo deslocamento ou pelo horário - normalmente dias de semana e horário comercial de trabalho.

O CBH-AP ainda não implementou a cobrança de recursos hídricos na Bacia Hidrográfica do Rio

\section{ASSUNTOS MAIS DEBATIDOS}

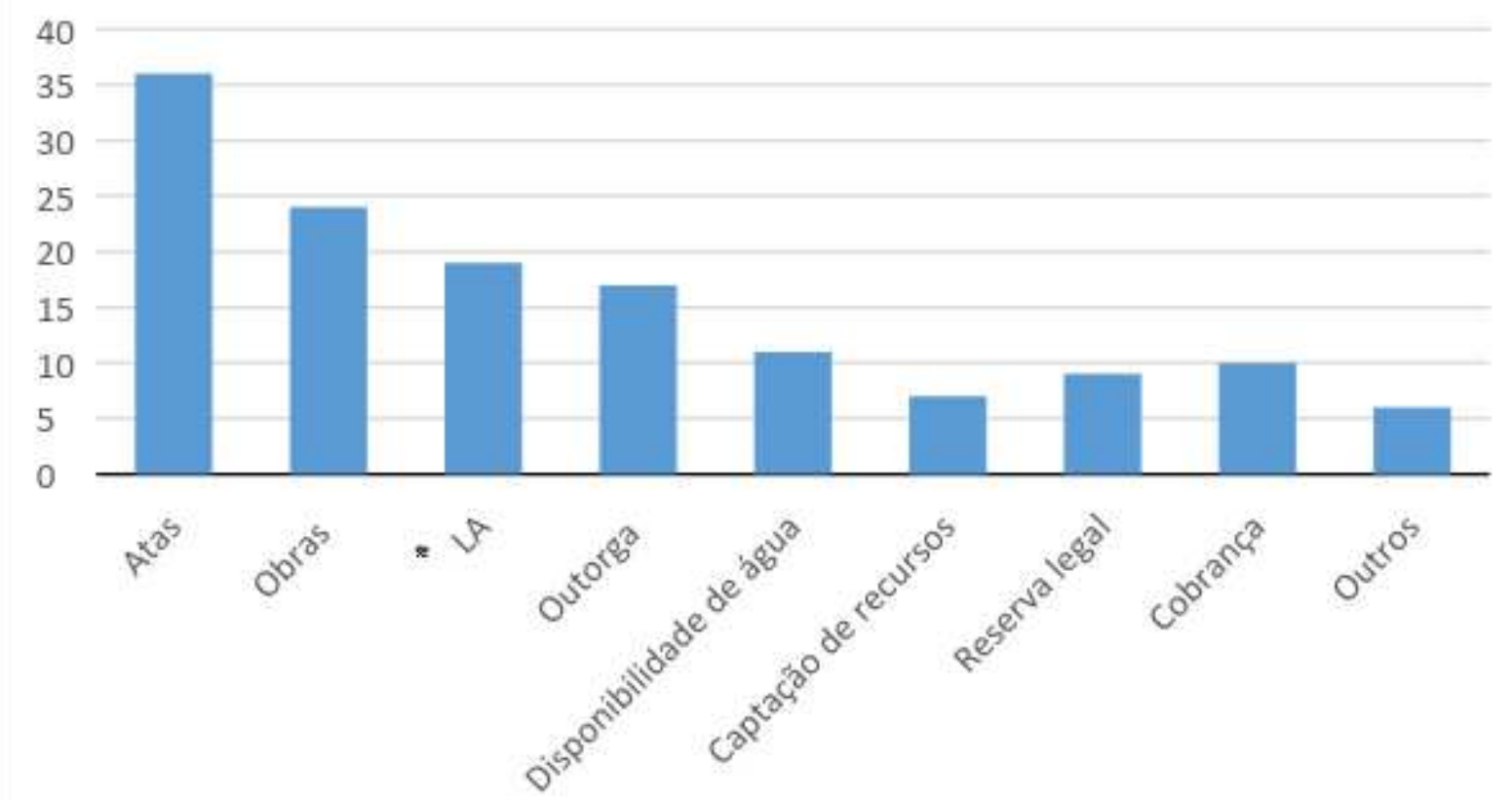

FIGURA 5 - Assuntos mais debatidos nas reuniões do Comitê de Bacia Hidrográfica dos Afluentes do Rio Preto, considerando o registro das atas no período de 2010 ao 10 trimestre de 2017. *LA - Licenciamento Ambiental.

FONTE: Elaborado pelo autor. 
Preto. Além disso, o comitê ainda não foi capaz de elaborar ou aprovar projetos na bacia a fim de captar recursos. A ausência de recursos financeiros no comitê o torna dependente da Agência Reguladora de Águas, Energia e Saneamento Básico do Distrito Federal - ADASA/DF que acaba sendo responsável por dar o suporte técnico e administrativo à instituição. Contudo, o quadro reduzido de servidores da agência e a dificuldade de integração entre as políticas setoriais e o atendimento da demanda da comunidade local dificultam a gestão no âmbito do comitê.

Apesar dos gargalos na gestão dos recursos hídricos no CBH-AP, na Bacia Hidrográfica do Rio Preto no DF, avanços também foram percebidos. Uma das atribuições que o comitê desempenha de forma satisfatória é o debate sobre a situação dos recursos hídricos na bacia. Nesse sentido, a EMBRAPA Cerrados, a Empresa de Assistência Técnica e Rural do Distrito Federal- EMATER/DF e a ADASA/DF são os principais atores em promover o conhecimento técnico e científico nesse campo.

Nas reuniões são apresentados dados de pesquisas em sub-bacias experimentais, que mostram os fatores que reduzem a disponibilidade de água na bacia e quais medidas devem ser adotadas para mitigar o impacto sobre os recursos hídricos. Todos os produtores rurais entrevistados ou seus representantes (membros do comitê), afirmaram que a prática do plantio direto é adotada na maioria das propriedades. Esse fato foi confirmado por um representante da EMATER/DF no comitê.

A prática do plantio direto permite que a água infiltre no solo de forma gradual, alimentando os aquíferos da região, além de dificultar o carreamento de sedimentos aos corpos hídricos e o surgimento de processos erosivos no solo. Apesar do avanço no uso do plantio direto, outra técnica de conservação da água e do solo, conhecida como terraceamento, não tem sido utilizada pelos produtores devido a interferências na operação do maquinário agrícola. Contudo, a maioria dos representantes do setor agrícola informa que os produtores estão dispostos a adequar os terraços à operação do maquinário em suas propriedades. Gradativamente, os produtores rurais da bacia - que atuam no comitê - estão incorporando a necessidade de adotar práticas conservacionistas e utilizar a água de modo racional.

Outro aspecto positivo na gestão dos recursos hídricos no comitê é que representantes do poder público (EMATER/DF e ADASA/DF), que participam da negociação alocada de água com produtores rurais inseridos em sub-bacias onde a demanda por água já supera a oferta, são também membros do CBH-AP ou participam das reuniões deste. Apesar das negociações de alocação de água serem firmadas fora do âmbito do comitê, as discussões desse processo negocial são levadas ao conhecimento dos membros do CBH-AP. O processo de alocação de água é o compromisso dos produtores rurais com o poder público, visando captar água para irrigação em períodos determinados em comum acordo. São formados grupos de irrigação, de forma que a captação exerça menor pressão nos cursos de água da região. A participação dos produtores rurais no processo de tomada de decisão fortalece a democratização da gestão dos recursos hídricos.

Na pesquisa de Britto \& Johnsson (2013), constatou-se que um dos aspectos positivos do Comitê Guandu (no Estado do Rio de Janeiro) é a participação e o engajamento dos atores sociais, não somente da sociedade civil, mas também dos outros integrantes. $\mathrm{O}$ amadurecimento do seu funcionamento é baseado no diálogo e na negociação 
entre os representantes dos diversos segmentos e na parceria entre os atores que representam o governo estadual e os diversos governos municipais.

Para que as negociações nos comitês de bacia hidrográfica sejam efetivas, é necessário que todos os interessados nos recursos hídricos da bacia tenham os seus interesses representados e que, além disso, eles sejam passíveis de discussão e deliberação em igualdade de condições. Isso constitui uma grande dificuldade para se obter a participação e representação de todos. Só é possível garantir a participação social equânime quando são dadas oportunidades iguais de acesso à informação aos diversos segmentos e atores, independentemente de sua origem e do seu grau de instrução (Saito, 2001). Membros de pequenas comunidades desassistidas, que participam das reuniões e deliberações dos comitês, não conseguem compreender termos mais técnicos discutidos geralmente por especialistas e membros do poder público, ficando alienados no processo de tomada de decisão.

Portanto, apesar das dificuldades operacionais do CBH-AP, sua criação pode ser considerada um avanço na gestão dos recursos hídricos da Bacia Hidrográfica do Rio Preto. Desde de sua criação o comitê tem, ainda que lentamente, evoluído nas discussões e nos encaminhamentos das reuniões. O fortalecimento dessa instituição necessita de um processo colaborativo entre os atores envolvidos na gestão hídrica. Esse processo demanda tempo e deve ser aprimorado de forma transparente, equânime e articulada.

\section{Integração na gestão hídrica: utopia?}

Historicamente, pode-se destacar que a gestão das águas no Brasil ocorreu de forma fragmentada e centralizada. Como destacam Abers \& Jorge (2005), ela ocorreu de forma fragmentada porque cada setor - energia elétrica, agricultura irrigada, saneamento, preservação ambiental - realizava o seu próprio planejamento e propunha medidas correlatas. Cada setor fazia isso de forma isolada, porque o governo federal e os governos estaduais (esses de forma mais esporádica) definiam a política das águas sem inputs dos governos municipais, dos usuários da água e da sociedade civil.

O gerenciamento integrado dos recursos hídricos - GIRH continua sendo um grande desafio. De acordo com a definição do Global Water Partnership - GWP, o GIRH é "um processo que promove o desenvolvimento e gerenciamento coordenado dos recursos hídricos, do uso e ocupação do solo e demais recursos relacionados visando à maximização do bem-estar social e econômico de forma equânime, sem comprometer a sustentabilidade vital dos ecossistemas" (GWP, 2010). Dessa forma, o GIRH é direcionado a um novo paradigma de gestão transversal entre diferentes setores usuários de recursos hídricos - como representado na Figura 6.

Portanto, considerando os interesses de diferentes setores e a necessidade de integração em diversos níveis, percebe-se a complexidade da aplicação do termo GIRH na gestão hídrica. Diferentes aspectos políticos, sociais, econômicos, ambientais, técnicos ou administrativos, para gerir os recursos hídricos em diferentes contextos territoriais, sustentam a ideia dessa complexidade.

Para Smits \& Butterworth (2006), devemos assumir uma perspectiva de governança local em comparação com outros grupos de interesse envolvidos no local, como o governo nacional, os órgãos de gestão de recursos hídricos e os diversos grupos da sociedade civil - incluindo o setor privado. Con- 
tudo, em alguns casos, como nas grandes regiões metropolitanas, a perspectiva da governança regional deve ser levada em conta na governança local.

Apesar de as instituições, em geral, estarem aderindo à corrente de gestão integrada da água como solução para o crescimento da demanda de água e sua contaminação, há críticas sobre a real aplicabilidade deste modelo. Biswas (2004) analisa o conceito de gestão integrada dos recursos hídri$\cos$, destacando a inviabilidade de sua aplicação no mundo real, tanto o conceito em si, como a sua implementação. Ele sustenta que o conceito continua sendo amorfo e que não existe acordo sobre temas fundamentais - como, por exemplo, os aspectos que deveriam ser integrados; como, por quem e se essa integração é possível em um sentido amplo.

A implementação e institucionalização da GIRH em escala nacional e local permanecem como desafios, sendo tal modelo questionado por muitos autores (Biswas, 2004; Goldmann, 2007; Jonker, 2007; Medema et al., 2008; Dobner, 2010; Muller,
2010). Há um debate sobre como essa expressão tem sido apropriada e difundida por diferentes atores de forma banal ou para ser utilizado apenas em normatizações de forma vaga.

Para Mostert (2006), a GIRH é ideológica, pois na prática são estabelecidas prioridades ao mesmo tempo em que são feitas escolhas políticas. Os gestores são os reais tomadores de decisões. Essas relações sociais e políticas influenciam a forma como o conceito de gestão é utilizado.

\subsection{Integração entre os instrumentos da gestão hídrica e ambiental - Outorga e Licenciamento Ambiental na Bacia Hidrográfica do Rio Preto}

A transversalidade da gestão da água é um fator que pesa na gestão desse recurso. No Distrito Federal, diversas instituições (SEAGRI, EMATER, ADASA, CAESB, IBRAM) possuem diferentes

\section{DIÁLOGO INTERSETORIAL NO GERENCIAMENTO INTEGRADO DOS RECURSOS HÍDRICOS}

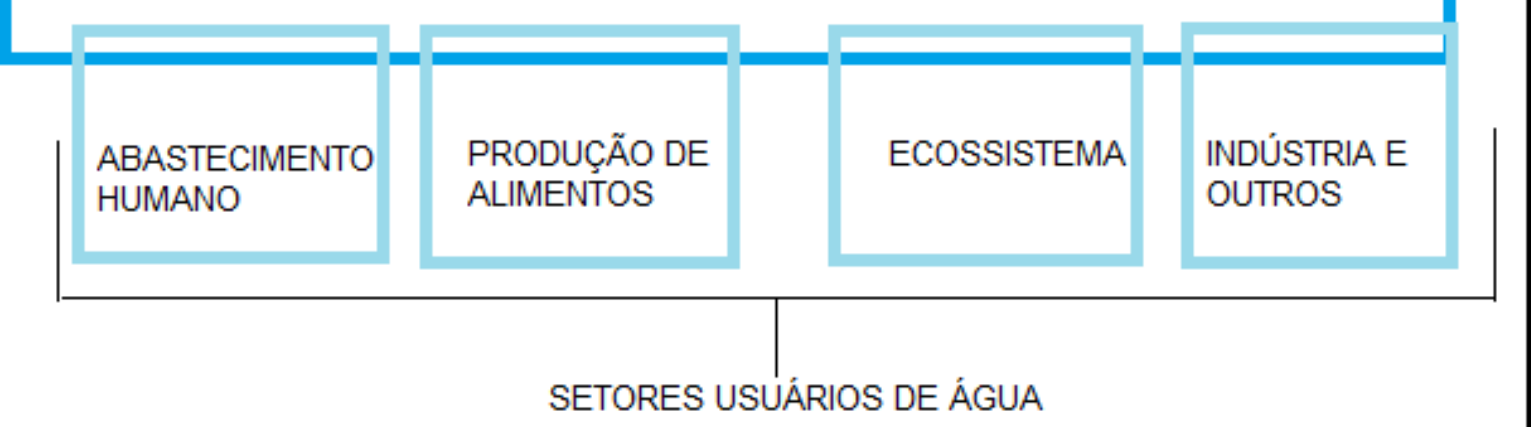

FIGURA 6 - Gerenciamento Integrado dos Recursos Hídricos e diálogos transversais entre diferentes setores. FONTE: GWP (2000). 
papéis na gestão da água. Na escala federal, a ANA, o ICMBIO, os Ministérios da Agricultura, do Meio Ambiente, de Minas e Energia, da Integração Nacional; também exercem diferentes funções no gerenciamento da água. O Diretor do Programa Nacional de Água e Energia Renovável de Israel, durante o Seminário das Águas (realizado em 22 março de 2017 - no MMA), criticou a quantidade de instituições que trabalham de formas diferentes e têm visões distintas sobre o uso da água.

Em Israel, onde a escassez de água é significativamente maior que no Brasil, não há essa fragmentação de órgão gerindo um mesmo recurso. $\mathrm{Na}$ visão do especialista, esse tipo de governança traz mais conflitos do que soluções para o uso adequado da água. São publicadas diversas normas - às vezes conflitantes - por diferentes instituições, sem qualquer tipo de análise integrada das políticas setoriais envolvidas. Esse modelo fragmentado de gestão, no qual não ocorre a integração entre os setores, tende a fracassar.

$\mathrm{Na}$ visão dos membros do $\mathrm{CBH}-\mathrm{AP}$, a maioria entende que a gestão ambiental não é integrada com a gestão de recursos hídricos. O fato do órgão que concede a licença ambiental não ser o mesmo que concede a outorga de uso de água, como é o caso do DF, favorece a desarticulação desses instrumentos. De modo geral, por parte dos irrigantes há muita reclamação dos procedimentos de licenciamento ambiental, principalmente a morosidade do processo até a expedição da licença. O produtor rural tem facilidade em adquirir a outorga de uso de água, mas não pode irrigar suas culturas porque ainda não possui a licença ambiental. Por parte do poder público, foi relatada a necessidade de melhorar os procedimentos para concessão de outorgas e licenças ambientais, de forma a garantir a água em qualidade e quantidade para os usuários - sem comprometer a manutenção ecológica na bacia.

No DF ainda não há uma base de dados comum entre a ADASA/DF, responsável por conceder as outorgas de uso de água, e o Instituto Brasília Ambiental-IBRAM/DF, responsável pela concessão das licenças ambientais. Essa fragmentação de dados prejudica a análise e a tomada de decisão dos gestores, especialmente em bacias como a Bacia Hidrográfica do Rio Preto, em que a demanda por água é maior do que sua oferta no período seco.

As outorgas no DF são concedidas sem qualquer tipo de análise ambiental da propriedade - como o estado de conservação das Áreas de Preservação Permanente- APP, da reserva legal e a vazão ecológica para manter os serviços ecossistêmicos. A gestão dos recursos hídricos, tanto no Distrito Federal quanto nas demais unidades federativas do Brasil, tem sido baseada apenas em dados hidrológicos. Os gestores têm se preocupado mais em fazer cálculos hidrológicos para ter conhecimento das vazões outorgáveis do que se preocupado em integrar outros aspectos presentes na bacia hidrográfica, que interferem diretamente ou indiretamente no ciclo hidrológico. Frequentemente, nos processos de concessão de outorga de uso de água e de licenças ambientais, não são considerados aspectos sociais, econômicos e ambientais existentes no território (Mesquita, 2017).

Um outro fator que chama a atenção na concessão de outorgas de uso de água e de licenças ambientais, é a fixação de um valor para a vazão ecológica. No Distrito Federal essa vazão é definida por resolução da ADASA, que estabelece um valor fixo de $20 \%$ da vazão de referência. Vestena et al. (2012) aponta que a definição de valores fixos, de vazões remanescentes - baseadas em dados 
hidrológicos históricos -, não é suficiente para a manutenção dos processos ecológicos na bacia.

A vazão ecológica deveria, na verdade, ser referendada por técnicos e especialistas do órgão ambiental. Em alguns estados como Rio de Janeiro, Goiás, Bahia e Rio Grande do Sul, a outorga e a licença ambiental são concedidas pelo órgão ambiental, reduzindo o descompasso na concessão desses instrumentos.

Contudo, no Distrito Federal não há uma análise por parte do órgão ambiental da vazão ecológica. Nos processos de licenciamento ambiental de irrigação, na área rural da Bacia Hidrográfica do Rio Preto, não há manifestações dos analistas ambientais a respeito da vazão ecológica. O CBH-AP, apesar da pressão de grandes produtores agrícolas, ainda não possui poder de influência sobre o processo de tomada de decisão para concessão de outorgas ou licenças ambientais.

O principal problema que se apresenta para a adoção de critérios meramente hidrológicos na concessão de outorgas, é que em bacias com uso intensivo dos recursos hídricos, como na Bacia Hidrográfica do Rio Preto, os critérios adotados tendem a não funcionar. É essencial que haja um plano de bacia, definindo critérios a serem adotados - de modo a alcançar objetivos pactuados entre todos atores envolvidos. Lopez \& Freitas (2007) apresentam problemas na adoção desses critérios: I) articulação reduzida com políticas setoriais; II) pouca participação dos usuários nas decisões; e III) pouca capacidade de identificação e previsão de conflitos pelo uso da água.

Portanto, ainda são grandes os desafios a serem enfrentados pelo CBH-AP na Bacia Hidrográfica do Rio Preto. A seguir serão apresentadas propostas de como enfrentar esses desafios na gestão dos recursos hídricos na bacia.

\section{Desafios da gestão descentralizada e integrada dos recursos hídricos}

Um primeiro desafio ao funcionamento dessa gestão descentralizadora é alcançar ou ao menos se aproximar, inicialmente, da integração proposta pela nova política de gestão das águas, suplantando a referida fragmentação que resultou na criação de inúmeras entidades para gerir a água e os seus usos - em diferentes âmbitos e níveis de governo. Contudo, como já mencionado neste texto, devem ser superados os limites do processo de negociação técnica e social em função do déficit de articulação entre as instâncias governamentais de gestão dos recursos hídricos; gestão ambiental; gestão de uso e ocupação do solo - bem como a comunicação e participação dos diferentes atores envolvidos.

A própria definição e delimitação da área a ser considerada para gestão e planejamento da bacia hidrográfica, resulta de uma construção política e social, fato que impacta a organização e a representação dos grupos sociais e sua participação nos novos arranjos institucionais (Fracalanza et al., 2009). Sendo assim, cada vez mais é preciso aumentar a capacidade governativa, desenvolvendo e aperfeiçoando os meios de interlocução e de administração do jogo de interesses.

As instituições democráticas podem contribuir para o desenvolvimento, essa contribuição pode vir com a criação de novos espaços e novas relações de poder, focando menos em resultados políticos e mais em meios de mudança que beneficiem as populações pobres e excluídas - redistribuindo prioridades e 
recursos para atender as suas necessidades (Gaventa \& Barret, 2010).

Contudo, nessa política descentralizadora, merece destaque a composição dos comitês locais, a forma de eleição, o funcionamento, a participação e a representação dos diferentes segmentos que podem influenciar de forma equivocada as decisões tomadas. A tendência de favorecer interesses de grupos prósperos ou de determinada categoria, compromete a voz dos mais desfavorecidos. Os comitês de bacias hidrográficas, responsáveis pela gestão em grandes áreas agrícolas, tendem a ter predominância dos grandes agricultores irrigantes, mais articulados e com maior poder de influência. A comunidade rural vulnerável e mais pobre, que também é usuária dos recursos hídricos, fica alienada do processo de tomada de decisão.

Na gestão dos recursos hídricos da Bacia Hidrográfica do Rio Preto, é importante atentar-se para a definição da bacia hidrográfica como unidade de planejamento. Na realidade, a maioria das gestões territoriais ocorre em diferentes unidades e escalas.

No Plano Diretor de Ordenamento Territorial do Distrito Federal - PDOT/DF, por exemplo, seu zoneamento é subdividido em áreas rurais e urbanas. Os limites das Regiões Administrativas do DF, das áreas de recarga dos aquíferos, do Zoneamento Ecológico e Econômico, não coincidem com os limites da bacia hidrográfica. Portanto, apesar da sua importância na gestão territorial, a gestão por bacia hidrográfica deve considerar as interações com as águas subterrâneas, as zonas econômicas, sociais e ambientais, pois não há coincidências de delimitações físicas entre elas.

Varis et al. (2014) fazem uma relação das dificuldades de implantação da boa governança dos recursos hídricos:
- $\quad$ Fragmentação setorial;

- Problemas com a configuração institucional (atribuições não claras) e coordenação;

- Pouco envolvimento dos atores envolvidos;

- Insuficiência de dados e informações;

- Ausência ou insuficiência de fundos;

- Dificuldade de focar na gestão da demanda de água ao invés da gestão da oferta;

- Gestão de emergência ao invés de gestão de longo prazo;

- Escassez de água e uso não sustentável desse recurso, causando problemas na qualidade da água;

- Falta de reuso e armazenamento de água;

- Ausência do uso de instrumentos econômicos e envolvimento do setor privado;

- Medo de abandonar métodos tradicionais por modelos mais modernos.

A maioria das dificuldades mencionadas pelos autores acima, se não todas, também são percebidas na Bacia Hidrográfica do Rio Preto no Distrito Federal e no seu comitê gestor. Os poderes dos comitês tendem a ser pouco tangíveis. Aprovar o plano de recursos hídricos da bacia tem implicações políticas ambíguas quando se leva em conta que o poder público tem, frequentemente, ignorado planos deste tipo. Quanto a outras competências dos comitês, não há garantias de que venham a ser cumpridas.

Faltam mecanismos legais que assegurem que decisões relacionadas à arbitração de conflitos sejam respeitadas pelos atores envolvidos ou que os órgãos gestores submetam as suas decisões sobre obras hídricas à deliberação dos comitês existentes (Abers \& Jorge, 2005). O entendimento geral é que o estado não enxerga esses organismos como órgãos públicos legítimos e, assim, não respeita as 
suas decisões. Só a legislação e a organização institucional não resolvem o problema com condições de sustentar a gestão.

A crise da água é, antes de tudo, uma crise de gestão desse recurso - mais do que de escassez ou de contaminação (Rebouças et al., 2006). A integração entre o conhecimento científico adquirido e a gestão hídrica subsidiam qualitativamente os usos múltiplos da água.

A incorporação de inovações tecnológicas na gestão, que vai desde o manancial até o usuário, é uma etapa importante no processo descentralizado e participativo na gestão hídrica. Nessa questão, a contribuição da universidade e dos institutos de pesquisa (públicos e privados) é a fonte de ampliação do conhecimento e de novos avanços tecnológicos (Tundisi, 2006).
O conhecimento de especialistas, oriundos das esferas pública, privada e da sociedade civil, com a negociação permanente, interdisciplinar e em relação direta com a sociedade; auxilia a integração da gestão hídrica. Quando a interdisciplinaridade e a complexidade não são consideradas na política pública hídrica, o desenho das políticas fica inadequado e as dificuldades da implantação aumentam. As instituições brasileiras, em geral, estão fundadas no conhecimento por setores, organizando-se por áreas de especialização. Assim, prevalecendo uma cultura fragmentada que dificulta a interação entre especialistas (Granja, 2008).

Considerando os desafios e dificuldades explanados nesse texto, foi elaborada a Tabela 1 com propostas resolutivas na gestão dos recursos hídricos na Bacia Hidrográfica do Rio Preto.

TABELA 1 - Desafios e propostas resolutivas na gestão dos recursos hídricos na Bacia Hidrográfica do Rio Preto.

\begin{tabular}{|c|c|}
\hline DESAFIOS & PROPOSTAS RESOLUTIVAS \\
\hline OUTORGA NEGOCIADA DE ÁGUA & $\begin{array}{l}\text { - Considerar na análise para concessão da outorga } \\
\text { aspectos ambientais, uso e ocupação do solo e as } \\
\text { águas subterrâneas; } \\
\text { - Ampliar a participação de instituições de ensino e } \\
\text { pesquisa na definição dos critérios para concessão } \\
\text { da outorga; } \\
\text { Unificar os dados de diferentes setores (agrícola, } \\
\text { ambiental, recursos hídricos e uso e ocupação do } \\
\text { solo) referentes às propriedades rurais na bacia. }\end{array}$ \\
\hline
\end{tabular}


ELABORAÇÃO DE PROJETOS

AMPLIAR A PARTICIPAÇÃO
- Promover o conhecimento técnico-científico permanentemente aos membros do $\mathrm{CBH} / \mathrm{AP}$ e às comunidades da bacia, considerando os aspectos sociais, ambientais e territoriais;

- Criar câmara técnica ou grupo de trabalho multidisciplinar no CBH/AP com a participação da sociedade civil, usuários, especialistas, instituições de ensino e pesquisa.

- Realizar reuniões do comitê em diferentes locais na bacia após ampla divulgação aos usuários;

- Realizar reuniões do comitê em diferentes locais na bacia após ampla divulgação aos usuários;

- Promover ações educativas nas comunidades de forma a emponderá-las nos processos de tomada de decisão;

- Definir critérios de representação nos organismos de bacia, de forma a impedir tanto a manipulação por grupos guiados por interesses próprios, como a possibilidade da instrumentalização pela administração pública;

- Motivar os atores envolvidos na gestão dos recursos hídricos na bacia.

\section{Conclusão}

A redemocratização brasileira, iniciada na década de 1980, veio acompanhada da ideia de redução do estado e expansão da descentralização, a fim de distribuir responsabilidades e garantir mais autonomia às entidades locais. A instituição de conselhos de educação, habitação, saúde, assistência social, meio ambiente e recursos hídricos; corrobora essa tendência descentralizadora.

$\mathrm{Na}$ área de gestão de recursos hídricos, esse processo se consolidou com a instituição da PNRH, que criou o SNGRH, em cujo âmbito foram instituídos os CBHs. A descentralização e a participação - assim como a integração intersetorial -, presentes nessa nova forma de gestão, são desafios a serem enfrentados para o alcance dos objetivos da política hídrica. A divergência entre os interesses de múltiplos segmentos, as fragilidades administrativas, os interesses políticos e econômicos, são fatores que dificultam o gerenciamento dos recursos hídricos.

A criação dos comitês de bacia parece ocorrer de acordo com múltiplas lógicas. Em alguns casos, por aspectos legais, em outros, por atores locais 
que se organizaram em alguns estados ou, por fim, por motivos financeiros ou legais. A participação nos comitês de bacia é prejudicada, entre outros fatores, por falta de: incentivos financeiros; apoio administrativo; vagas ociosas; e falhas de comunicação entre os membros e a comunidade. Interesses individuais se sobrepõem a interesses coletivos da bacia, mostrando resquícios do clientelismo na gestão hídrica.

No CBH-AP, predominam discussões voltadas ao atendimento das demandas de grandes produtores rurais irrigantes presentes na Bacia Hidrográfica do Rio Preto. Nesse comitê, não há participação de segmentos da sociedade civil de proteção ambiental, da academia ou de pequenos produtores. As discussões estão direcionadas aos procedimentos para concessão de outorga para uso de água, implantação de barragens e regularização ambiental da propriedade. A ausência da elaboração e de execução do plano de bacia, além da carência de elaboração de projetos para captação de recursos e a falta de incentivos para produtores que adotem práticas conservacionistas, são fatores que comprometem a operacionalidade e gestão do comitê.

Apesar das dificuldades na gestão do CBH-AP, mencionadas acima, gradativamente o comitê tem apresentado aspectos positivos. O conhecimento técnico e científico da situação hídrica na bacia do Rio Preto, levado pela EMBRAPA Cerrados, EMATER e ADASA, tem contribuído para aumentar a consciência de produtores rurais que participam das reuniões do comitê. A maioria das propriedades rurais na bacia utilizam a técnica do plantio direto. Os produtores rurais, membros do comitê, relataram estarem sensíveis ao uso de terraços ou outras técnicas de conservação que aumentem a disponibilidade de água na região e evitem processos erosivos. Além disso, é um senso comum entre os membros do CBH-AP a necessidade de se alocar água no período seco.

Com relação a gestão integrada de recursos hídricos, críticos desse modelo classificam essa integração como ideológica e intangível. A dificuldade de coordenar diferentes setores com interesses divergentes e a banalização do uso do termo GIRH, por diferentes atores, sustentam os debates críticos. Contudo, em políticas concorrentes (ambiental e hídrica) na gestão de um bem comum como a água, essa articulação reduz conflitos futuros. A interface se faz presente em outras políticas (agrícola, saneamento, uso e ocupação do solo), evidenciando a complexidade de aplicação da integração na gestão.

$\mathrm{Na}$ Bacia Hidrográfica do Rio Preto, a concessão de outorgas e licenças ambientais ainda carece de análise ambiental integrada. As outorgas de uso de água são concedidas baseadas em dados hidrológicos históricos, sem levar em consideração a ocupação do território e os aspectos ambientais. Ambos instrumentos não foram capazes de controlar a situação de escassez hídrica crítica do Distrito Federal no período seco. Esses instrumentos precisam ser revistos por especialistas de instituições de ensino e pesquisa, pela sociedade e pelo poder público - de forma transparente e participativa. A conjugação dos dados ambientais, hídricos e territoriais - existentes nesse processo de revisão - é fundamental para a gestão dos recursos hídricos não fracassar.

Portanto, o processo de descentralização na gestão hídrica não é, necessariamente, democrático ou implica em participação e representatividade dos membros que compõem os CBHs. Além disso, não há garantia da autonomia dessas organizações e de melhora na prestação dos serviços em prol de 
interesses coletivos. É fundamental uma integração entre o conhecimento científico adquirido e o gerenciamento dos recursos hídricos.

Processos como a aprendizagem social e a construção de consensos gradativos entre os atores envolvidos, são essenciais para o fortalecimento do processo de tomada de decisão e da governança da água. Apesar das dificuldades operacionais, a criação dos comitês é bem-vinda. É melhor tê-los do que não. O desafio é tentar moldá-los para que cumpram os objetivos que lhes cabem na PNRH e atendam as demandas dos usuários da bacia de forma equânime.

\section{Referências}

Abers, R.; Jorge, K. "Descentralização da gestão da água: por que os comitês de bacia estão sendo criados?" Ambiente \& Sociedade, 8 (2), 99-124, 2005.

Agrawal, A.; Ribot, J. Analyzing Decentralization: a Frame Work with South Asian and East African Environmental Cases. World Resources Institute Institutions and Governance Program Working Paper Series, 2000. Disponível em: http:// pdf.wri.org/eaa_wp1.pdf.

ANA - Agência Nacional das Águas. Cadernos de Capacitação em Recursos Hídricos. O Comitê de Bacia Hidrográfica: o que é e o que faz? Brasília, SAG, 2011. Disponível em: http://arquivos.ana.gov.br/institucional/sge/CEDOC/ Catalogo/2012/CadernosDeCapacitacao1.pdf.

ANA-Agência Nacional de Água. Conjuntura dos recursos hídricos: informe 2015. Brasília: ANA, 2015. 88p. Disponível em: http://www.ana.gov.br.

Arretche, M. Mitos da descentralização: mais democracia e eficiência nas políticas públicas? Revista Brasileira de Ciências Sociais, 11(31), 1996. Disponível em: http://www. anpocs.org.br/portal/publicacoes/rbcs_00_31/rbcs31_03. htm.

Biswas, A. Integrated Water Resources Management: A
Reassessment: A Water Forum Contribution. International Water Resources Association. Water Internacional. Washington D.C. 29, (2), 248-256, 2004.

Blair, H. Participation and Accountability at the Periphery: Democratic Local Governance in Six Countries. World Development, 28(1), 21-39, 2000.

Borges, M. E. S. Mapeamento geomorfológico da bacia do Rio Preto e sua relação com o uso agrícola. Brasília, Dissertação (Mestrado em Geografia) - UnB, 2008.

Brannstrom, C. Decentralising Water Resource Management in Brazil. European Journal of Development Research, 16(1), 214-234, 2004.

Britto, A. L.; Johnsson, R. M. F. Gestão Participativa e Integrada das Águas na Região Metropolitana do Rio de Janeiro: Uma Análise do Funcionamento dos Comitês de Bacia Hidrográfica. In: VIII Congresso Iberico sobre Gestion e Planification del Agua, 2013. Disponível em: http:// revistas.lis.ulusiada.pt/index.php/8cigpa/article/view/332/0.

CBHRSF - Comitê de Bacia Hidrográfico do Rio São Francisco. Estrutura Organizacional do Comitê de Bacia Hidrográfico do Rio São Francisco. Disponível em: http:// cbhsaofrancisco.org.br. Acesso em: ago.2016.

Dobner, P. Wasserpolitik. Zur politischen theorie, praxis und kritik globaler governance. Suhrkamp, Belin, Germany, 2010. Disponível em: http://www.suhrkamp.de/ buecher/wasserpolitik-petra_dobner_29558.html. Acesso em: fev.2016.

Fracalanza, A. P.; Campos, V. N. O.; Jacobi, P. R. Governança das águas da Região Metropolitana de São Paulo (Brasil) - o caso do Comitê de Bacia Hidrográfica do Alto Tietê. In: Jacobi, P. R.; Sinisgalli, P. A. (Org.). Dimensões político institucionais da governança da água na América Latina e Europa. São Paulo, Annablume. p. 57-81, 2009.

Fracalanza, A. P.; Campos, V. N. O. Governança das águas no Brasil: Conflitos pela apropriação da água e a busca da integração como consenso. Ambiente \& Sociedade, 8(02), 365-382, 2010.

Gaventa, J.; Barret, G. So What The Diference Does It Make. Mapping the Outcomes of Citzen Engagement. IDS Woeking Paper 347. Brighton, Institute for Development Studies, 
2010. doi: 10.1111/j.2040-0209.2010.00347.

Granja, S. I. B Negociação na governança da água: inovações na construção de consensos em comitês de bacia hidrográfica. Water Governance Game para o Comitê do Alto Tietê. São Paulo, Tese (Doutorado em Ciência Ambiental) - USP, 2008.

Goldmann, M. How 'Water for All!' policy became hegemonic: the power of the World Bank and its transnational policy networks. Geoforum, 38, 786-800, 2007. doi: 10.1016/j. geoforum.2005.10.008

GWP - Global Water Partnership. IWRM at a Glance, 2000. Disponível em http://www.gwp.org/en/ToolBox/ABOUT/ IWRM-Plans. Acesso em: fev.2016.

GWP - Global Water Partnership. Abaout IWRM, 2010. Disponível em http://www.gwp.org/en/GWP-Caribbean/ WE-ACT/About-IWRM/. Acesso em: ago. 2016.

IBAMA - Instituto Brasileiro do Meio Ambiente e Recursos Naturais Renováveis. Norte Energia é autorizada a encher reservatório para operação de Belo Monte, no Pará, 2015. Disponível em: http://www.ibama.gov.br/noticias/66-2015/ 208-norte-energia-e-autorizada-a-encher-reservatorio-para-operacao-de-belo-monte-no-para. Acesso em ago. 2016.

Jacobi, P. R.; Monteiro, F. Social capital and institutional performance: methodological and theoretical discussion on the water basin committees in metropolitan São Paulo - Brazil. Ambiente \& Sociedade, 9(2), 25-45, 2006.

Jacobi, P. R.; Sinisgali, P. A. Governança da água no Brasil: dinâmica da política nacional e desafios para o futuro. In: Jacobi, P. R.; Sinisgali, P. A. Governança da água e políticas públicas na América Latina e Europa. São Paulo, Annablume, p. 49-82, 2009.

Jonker, L. Integrated water resources management: the theory-praxis-nexus, a South African perspective. Physics and Chemistry of the Earth, Parts A/B/C, 32, 1257-1263, 2007. doi: 10.1016/j.pce.2007.07.031

Lopez, A.V.; Freitas, M. A. S. A alocação de água como instrumento de gestão de recursos hídricos: experiências brasileiras. REGA, 4(1), 5-28, 2007.

Machado, B. G. F. Análise econômica aplicada à decisão sobre alocação de água entre os usos irrigação e produção de energia elétrica: o caso da bacia do Rio Preto. Brasília,DF. Dissertação (mestrado em tecnologia ambiental e recursos hídricos). UnB. p.145, 2009.

Manor, J. User Commitees: A Potencially Damaging Second Wave Descentralization. European Journal of Development Research, 6(1), 192-213, 2004.

Medema, W.; McIntosh, B. S.; Jeffrey, P. J. From premise to practice: a critical assessment of integrated water resources management and adaptive management approaches in the water sector. Ecology and Society, 13(2), 29, 2008. Disponível em: http://www.ecologyandsociety.org/vol13/iss2/art29/

Mesquita, L. F. G. Gestão de Recursos Hidricos na Bacia Hidrográfica do Rio Preto: Atores, Ações e Conflitos. Brasília, Dissertação (Mestrado em Desenvolvimento Sustentável) - UnB, 2017.

Moreira, T. M. X. Gestão Participativa no Ceará: Análise dos Comitês da Sub-Bacias Hidrográficas do Baixo e Médio Jaguaribe. Ceará, Dissertação (Mestrado em Engenharia Hidráulica) - UFC, 2013.

Mostert, E. Integrated Water Resources Managemente in Netherlands: how conceptions funtions. Journal of Contemporary Water Research \& Education, 135, 19-27, 2006.

Muller, M. Fit for purpose: taking integrated water resources management back to basics. Irrigation and Drainage Systems, 24(3-4), 161-175, 2010. doi: 10.1007/s10795010-9105-7

Prota, M. G. Análise do processo participativo na gestão dos recursos hídricos no Estado de São Paulo: Um estudo de caso do comitê de bacia hidrográfica do Tietê - Jacaré. São Paulo, Dissertação (Mestrado em Ciências, Saúde Ambiental) - USP, 2011.

Rebouças, A. C.; Braga, B.; Tundisi, J. G. Águas Doces no Brasil: Capital Ecológico, Uso e Conservação. 3. ed. São Paulo: Escrituras, 2006.

Ribot, J. Representation, Citizenship and public Domain in Democratic Development. p. 43-49, 2007.

Robinson, M. Does Decentralisation Improve Equity and Efficiency in Public Service Delivery Provision. IDS Bulletin, 38(1), 7-17, 2007. 
Saito, C. H. Política Nacional de Recursos Hídricos e o Sistema Nacional de Gerenciamento dos Recursos Hídricos. In: Educação Ambiental: Curso Básico à Distância. Documentos e legislação de educação ambiental. MMA, v.5. 2. ed. Ampliada, 2001.

Schultze, M. S.; Köppel, J.; Gomes, E. T. A. Governança da bacia hidrográfica do rio São Francisco: desafios de escala sob olhares inter e transdisciplinares. Revista Brasileira de Ciências Ambientais, 36, 19-44, 2015.

Smits, S.; Butterworth, J. Literature review: local government and Integrated Water Resources Management. Logo Water Project, 2006. Disponível em http://www.iclei-europe.orgl. Acesso em: fev. 2016.
Tundisi, J. G. Novas perspectivas para gestão dos recursos hídricos. Revista USP, 70, 24-35, 2006. Disponível em: http://www.revistas.usp.br/revusp/article/ view/13529/15347.

Varis, O.; Enckell, K.; Keskinen, M. Integrated water resources management: horizontal and vertical explorations and the 'water in all policies' approach. International Journal of Water Resources Development, 30(3), 433-444, 2014.

Vestena, L. R.; Oliveira, E. D.; Cunha, M. C.; Thomaz, E. L. Vazão ecológica e disponibilidade hídrica na bacia das Pedras, Guarapuava-PR. Ambi-Agua, 7(3), 212-227, 2012. 